Check for updates

Cite this: Mater. Chem. Front., 2020, 4, 3616

Received 1st July 2020

Accepted 27th July 2020

DOI: 10.1039/d0qm00437e

rsc.li/frontiers-materials

\section{A new family of liquid and solid guanidine-based n-type dopants for solution-processed perovskite solar cells $\dagger$}

\author{
Hidenori Nakayama, (D) ${ }^{a b c}$ Julia A. Schneider, (D) ${ }^{\text {bcd }}$ Mina Faust, ${ }^{b}$ Hengbin Wang, (D) \\ Javier Read de Alaniz (D) ${ }^{\text {bc }}$ and Michael L. Chabinyc (D)*bc
}

\begin{abstract}
We present a series of new dopants based on a bicyclcic guanidine-type structure, 1,5,7-triazabicyclo[4.4.0] dec-5-ene (TBD), for organic semiconductors. A series of TBD derivatives that were alkylated at the 7-position were synthesized and their physical properties were determined. These stable dopants were shown to be effective $n$-type dopants for [6,6]-phenyl- $C_{61}$-butyric acid methyl ester $\left(P C_{61} B M\right)$, poly $\left\{\left[N, N^{\prime}\right.\right.$-bis $(2$ octyldodecyl)naphthalene-1,4,5,8-bis(dicarboximide)-2,6-diyl]-alt-5,5'-(2,2' - bithiophene)\} (P(NDI2OD-T2)) and 3,9-bis(2-methylene-(3-(1,1-dicyanomethylene)-indanone))-5,5,11,11-tetrakis(4-hexylphenyl)-dithieno $\left[2,3-d: 2^{\prime}, 3^{\prime}-d^{\prime}\right]-s$-indaceno[1,2-b:5,6-b'] dithiophene (ITIC). Films of $\mathrm{PC}_{61} \mathrm{BM}$ doped with 10 mol\% of a dimeric derivative of TBD had electrical conductivities of $0.065 \mathrm{~S} \mathrm{~cm}^{-1}$. The utility of the dopants was further shown by doping electron transport layers of $\mathrm{PC}_{61} \mathrm{BM}$ with $2 \mathrm{TBD}-\mathrm{C} 10$ for methyl ammonium lead iodide $\left(\mathrm{MAPbl}_{3}\right)$ solar cells leading to improved fill factors and PCEs relative to undoped ETLs.
\end{abstract}

\section{Introduction}

The use of organic semiconductors in applications, such as solar cells, light-emitting diodes, field-effect transistors, and thermoelectric devices, presents a need for efficient dopants. ${ }^{1-3}$ Electrical doping of organic semiconductors is necessary to control their conductivity, fill electronic trap states, and to modify carrierinjection barriers at interfaces by shifting line-up of transport levels. Particularly sought after are n-type dopants for transport layers in solar cells and light emitting diodes. While n-type dopants with low ionization potentials, e.g. tetrathiafulvalene $(\mathrm{TTF}),{ }^{4,5}$ can be used with a wide variety of organic semiconductors they are not stable under ambient conditions due to their low oxidation potentials. In addition, the dopant must also be incorporated into the semiconductor uniformly which is particularly important for transport layers in solar cells.

A number of strategies have been used to develop air-stable n-type dopants. Latent species have been used by generating

\footnotetext{
${ }^{a}$ Electronics Materials and New Energy Laboratory, Mitsubishi Chemical Corporation, Yokohama R\&D Center 1000, Kamoshida-cho, Aoba-ku, Yokohama 227-8502, Japan

${ }^{b}$ Materials Department, University of California, Santa Barbara, California 93106, USA. E-mail: mchabinyc@engineering.ucsb.edu

${ }^{c}$ Mitsubishi Chemical Center for Advanced Materials, University of California, Santa Barbara, California 93106, USA

${ }^{d}$ Department of Chemistry, Fordham University, Bronx, New York 10458, USA $\dagger$ Electronic supplementary information (ESI) available. See DOI: 10.1039/ d0qm00437e
}

the reductive species in situ from a stable precursor, for example the hydride-donor leuco crystal violet (LCV) is generated from the crystal violet salt and benzimidazoline radicals. ${ }^{6}$ Other strategies include the use of weak bonds that allow cleavage coupled with electron transfer, e.g. a dimer of the 2,3-dihydro- $1 \mathrm{H}$-benzimidazole (2-Cyc-DMBI) ${ }_{2}{ }^{7}$ or photoactivation of the electron transfer raction. ${ }^{8}$ Organometallic species have been designed such that they may be stable in their undoped form or leverage the latent dopant strategy. ${ }^{3,9,10}$

Tertiary amines have been explored as n-type dopants. ${ }^{11-14}$ Tetrakis(dimethylamino)ethylene (TDAE) is a strong reducing agent and has been used to n-type dope organic semiconductors or to compensate for p-type doping. ${ }^{15}$ A drawback of TDAE is its volatility, but appropriate functionalization to increase its mass has led to effective n-type doping while still maintaining its solubility. ${ }^{16}$ The electron transfer reactions of cyclic amines such as diazabicyclo(5.3.0)non-5-ene (DBN) and 1,8diazabicyclo(5.4.0)undec-7-ene (DBU) with $\mathrm{C}_{60}$ have also been examined. ${ }^{17,18}$ DBU was found to react with $\mathrm{C}_{60}$ by electron transfer to form the radical ions $\mathrm{C}_{60}{ }^{-}$and $\mathrm{DBU}^{+}$, followed by formation of a diamagnetic adduct with and optical absorbance in the near infrared region. ${ }^{17}$ Recently addition of DBU was found to lead to increases in the electrical conductivity of $[6,6]$ phenyl- $C_{61}$-butyric acid methyl ester $\left(\mathrm{PC}_{61} \mathrm{BM}\right)$, poly $\left\{\left[N, N^{\prime}\right.\right.$-bis (2-octyldodecyl)naphthalene-1,4,5,8-bis(dicarboximide)-2,6-diyl]alt-5,5'-(2,2'-bithiophene) $\} \quad(\mathrm{P}(\mathrm{NDI} 2 \mathrm{OD}-\mathrm{T} 2))$ and 3,9-bis(2methylene-(3-(1,1-dicyanomethylene)-indanone))-5,5,11,11-tetrakis (4-hexylphenyl)-dithieno[2,3- $\left.d: 2^{\prime}, 3^{\prime}-d^{\prime}\right]-s$-indaceno[1,2-b:5,6- $\left.b^{\prime}\right]$ 
<smiles>C1CN=C2NCCCN2C1</smiles>

TBD
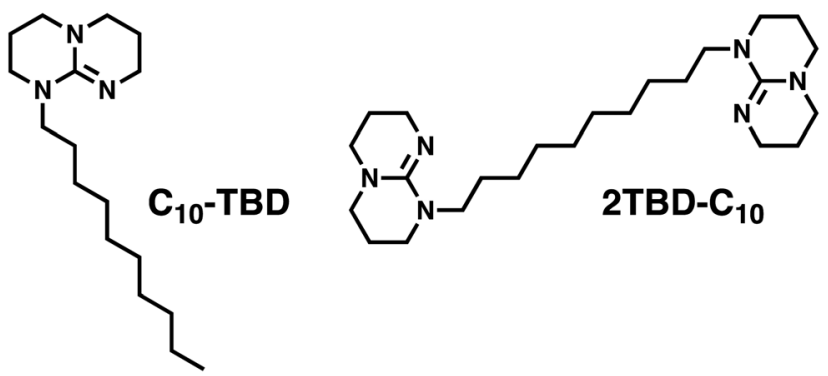

Fig. 1 The chemical structures of $n$-dopants based on 1,5,7-triazabicyclo [4.4.0]dec-5-ene (TBD)

dithiophene (ITIC).$^{19}$ Electron spin resonance (ESR) demonstrated the formation of radical species in each case, but the mechanism of doping and whether adducts were formed were not explored. Similarly 1-( $o$-tolyl) biguanide was found to dope $\mathrm{PC}_{61} \mathrm{BM}$ and used as an electron transport layer in MAPbI3 solar cells. ${ }^{20}$ For many tertiary amines, like DBU, their oxidation potential is such that the electron transfer reaction with many organic semiconductors is not thermodynamically favorable and either close contact of the resulting charge separated species or a subsequent reaction makes the doping process favorable.

Herein, we present a series of new triazabicyclodecene-based n-dopants with varying physical properties, namely TBD, iPrTBD, Me-TBD, C10-TBD, 2TBD-C10 (Fig. 1). TBD is a wellknown catalyst for transesterification and is considered a superbase. ${ }^{21,22}$ We are not aware of its use as a dopant for organic semiconductors. The chemistry of TBD allows for simple substitution at the nitrogen atom in the 7-position allowing for control of its volatility and physical state at room temperature. There have been relatively few reports of a systematic variation of the structure of n-type dopants for organic semiconductors. ${ }^{3,7,23,24}$ We therefore examined the impact of this functionalization on the performance as dopants in several organic semiconductors including $\mathrm{PC}_{61} \mathrm{BM}, \mathrm{P}(\mathrm{NDI} 2 \mathrm{OD}-\mathrm{T} 2)$ and ITIC. Their utility was further shown by doping electron transport layers of $\mathrm{PC}_{61} \mathrm{BM}$ with 2TBD-C10 in methyl ammonium lead iodide $\left(\mathrm{MAPbI}_{3}\right)$ solar cells leading to improved fill factors and PCEs relative to undoped ETLS.

\section{Results and discussion}

\section{Design and synthesis of TBD-based dopants}

We based our investigation of n-type dopants around bicyclic guanidine derivatives (Fig. 1). The parent compound is 1,5,7triazabicyclo[4.4.0]dec-5-ene (TBD), which is considered a superbase because of its high Brønsted basicity. The three nitrogen atoms around the central carbon atom provide three equivalent resonance structures, sometimes referred to as Y-aromaticity because of the cross conjugation through a central atom. ${ }^{25,26}$ By introducing alkyl substituents on TBD, we can alter its physical characteristics and its reactivity, hindering possible side reactions such as nucleophilic substitution with organic semiconductors.

7-Methyl-1,5,7-triazabicyclo[4.4.0]dec-5-ene (Me-TBD) was commercially available and used without further purification. TBD was readily alkylated with primary and secondary alkyl halides by deprotonating with sodium hydride and quenching with the alkyl bromide to yield iPr-TBD, C10-TBD, and 2TBD-C10. In contrast, we found that tertiary alkyl halides were not reactive under the conditions used. Details of the synthetic procedure are given in the ESI, $\dagger$ and NMR spectra of the compounds are given in Fig. S1-S3 (ESI $\dagger$ ). TBD is a crystalline white solid, but Me-TBD, iPr-TBD, and C10-TBD are oils, with iPr-TBD being by far the most viscous. 2TBD-C10 is a white powdery solid likely due to the presence of two TBD units per molecule. All of the derivatives are readily soluble in both polar and non-polar organic solvents, as well as water and methanol. This allows for versatile processing, employing either blends or sequential applications with anti-solvents. As well, this dopant family can be isolated and purified in non-anhydrous solvents and stored in air.

The structure of TBD bearing three external nitrogen atoms provides the potential for constructing quaternary ammonium salts via $N$-alkylation of the tertiary amines. As such, our reaction conditions were designed to minimize this possibility by keeping TBD in excess relative to the alkyl halide whenever feasible. The reaction of TBD with 1,4-dibromobutane was a notable exception that led exclusively to an intramolecular cyclization yielding a TBD derivative with a fused 7-membered ring (see ESI, $\dagger$ and Fig. S4). With shorter chains it appears the proximity of the secondary alkyl bromide to the Schiff base nitrogen facilitates intramolecular cyclization over the reaction with a second equivalent of TBD. As the resulting cyclic product with 1,4-dibromobutane is already cationic it was eliminated from our studies.

Our principle motivation behind modifying commercially available TBD was to enhance the stability of the dopant during processing. The volatility of dopants can drastically alter their concentration in thin films after coating and thermal annealing. To this end, we quantified the thermal stability of our dopants through thermal gravimetric analysis (TGA) (Fig. S5, ESI $\uparrow$ ). We found that modifying TBD with short alkyl chains, especially branched isopropyl groups, led to much lower initial decomposition temperatures. Longer alkyl chains like decyl, on the other hand, increased the thermal stability. 2TBD-C10, a solid like TBD, but with the added mass of the decyl chain, showed the highest thermal stability, with an initial decomposition temperature around $270{ }^{\circ} \mathrm{C}$.

\section{Electronic properties}

In order to act as efficient n-dopants, the TBD moiety must be readily oxidized to allow electron transfer to the organic semiconductor. Density functional theory (DFT) calculations show the highest occupied molecular orbital (HOMO) of Me-TBD 
having contributions from the nitrogen atoms with a node at their central carbon atom as expected (Fig. S6, ESI $\dagger$ ). We expect the series to behave similarly due to the simple alkyl substitution and used cyclic voltammetry $(\mathrm{CV})$ to compare the oxidation potentials of C10-TBD and 2TBD-C10 (Fig. S7, ESI $\dagger$ ). Both dopants showed highly irreversible oxidation potentials near $\approx 1.0 \mathrm{~V}$ relative to a ferrocene/ferrocenium $\left(\mathrm{Fc} / \mathrm{Fc}^{+}\right)$reference. This close match suggests that the two tethered TBD moieties in 2TBD-C10 behave independently. The oxidation potential from CV represents an ionization energy (HOMO level) of about $5.1 \mathrm{eV}$ for both dopants that is intermediate between other comparable tertiary amine dopants. TDAE is a strong reducing agent with an oxidation potential of $\approx-1 \mathrm{~V} v s . \mathrm{Fc} / \mathrm{Fc}^{+} \cdot{ }^{27,28}$ The oxidation potential of DBU has not been reported in studies of its use as a dopant, but it is a weaker reducing agent than TDAE. ${ }^{19}$ We used DFT to calculate the difference in gas-phase ionization energy between TBD-Me and DBU and find that TBD-Me is $0.45 \mathrm{eV}$ easier to ionize. The TBD series should therefore provide improved stability in ambient relative to TDAE and a higher driving force for electron transfer than DBU.

\section{n-Type doping of organic semiconductors}

We compared the performance of the new TBD-based dopants to $\mathrm{DBU}$ as a dopant for $\mathrm{PC}_{61} \mathrm{BM}$. $\mathrm{PC}_{61} \mathrm{BM}$ is a key material other as a component in organic solar cells ${ }^{29}$ and as an electron transport layers in other applications. ${ }^{15}$ The in-plane electrical conductivities of doped $\mathrm{PC}_{61} \mathrm{BM}$ films indicate that 2TBD-C10 gives the best conductivity of the series of dopants and gives higher performance than DBU (Fig. 2 and Table S1, ESI $\dagger$ ). The dopants were added over a range of doping ratios, 0.1 to $10 \mathrm{~mol} \%$ and a super-linear relationship was found between the electrical conductivity and doping ratio (Fig. 2). The data fits well to a simple power law $\left(y=y_{0}+A x^{\alpha}\right)$ with $\alpha$ of $\approx 1.3$; super-linear behavior is a common feature of hopping conduction in molecular semiconductors. ${ }^{30}$ It is notable that the electrical conductivity of $\mathrm{PC}_{61} \mathrm{BM}$ films doped with 2TBD-C10 $\left(6.5 \times 10^{-2} \mathrm{~S} \mathrm{~cm}^{-1}\right)$ is as high as that of films doped with (2-Cyc-DMBI $)_{2}$ : the maximum conductivity of (2-Cyc-DMBI) $)_{2}$ doped $\mathrm{PC}_{61} \mathrm{BM}$ films is reported to be $4.7 \times 10^{-3} \mathrm{~S} \mathrm{~cm}^{-1}$ at $10 \mathrm{~mol} \%$ addition. ${ }^{7}$ If each dopant led to the formation of 1 charge carrier, then the electron mobility can be estimated as $\approx 4 \times 10^{-3} \mathrm{~cm}^{2} \mathrm{~V}^{-1} \mathrm{~s}^{-1}$ at $10 \mathrm{~mol} \%$ and $\approx 1 \times$ $10^{-2} \mathrm{~cm}^{2} \mathrm{~V}^{-1} \mathrm{~s}^{-1}$ at $1 \mathrm{~mol} \%$ based on a mass density of $\mathrm{PC}_{61} \mathrm{BM}$ of $\approx 1.5 \mathrm{~g} \mathrm{~cm}^{-3}$. These values are comparable to mobilities of $\approx 4 \times 10^{-2} \mathrm{~cm}^{2} \mathrm{~V}^{-1} \mathrm{~s}^{-1}$ extracted from the current-voltage characteristics of thin film transistors of $\mathrm{PC}_{61} \mathrm{BM}$ doped with $\sim 1 \mathrm{~mol} \%$ of $\mathrm{N}$-DMBI. ${ }^{31}$ While it is difficult to quantitatively extract the efficiency of doping, it must be relatively high otherwise the carrier mobility would need to be larger than typically observed to account for the electrical conductivity. The effectiveness of 2TBD-C10 as a dopant can partly be explained by its good miscibility with $\mathrm{PC}_{61} \mathrm{BM}$. The AFM topography images of doped $\mathrm{PC}_{61} \mathrm{BM}$ films show no aggregation or phase separation for each concentration and look similar to that of a pristine PCBM film (Fig. S8, ESI $\dagger$ ).

We find that the alkylation of the 7-position of TBD affects both the electrical conductivity and processability of doped

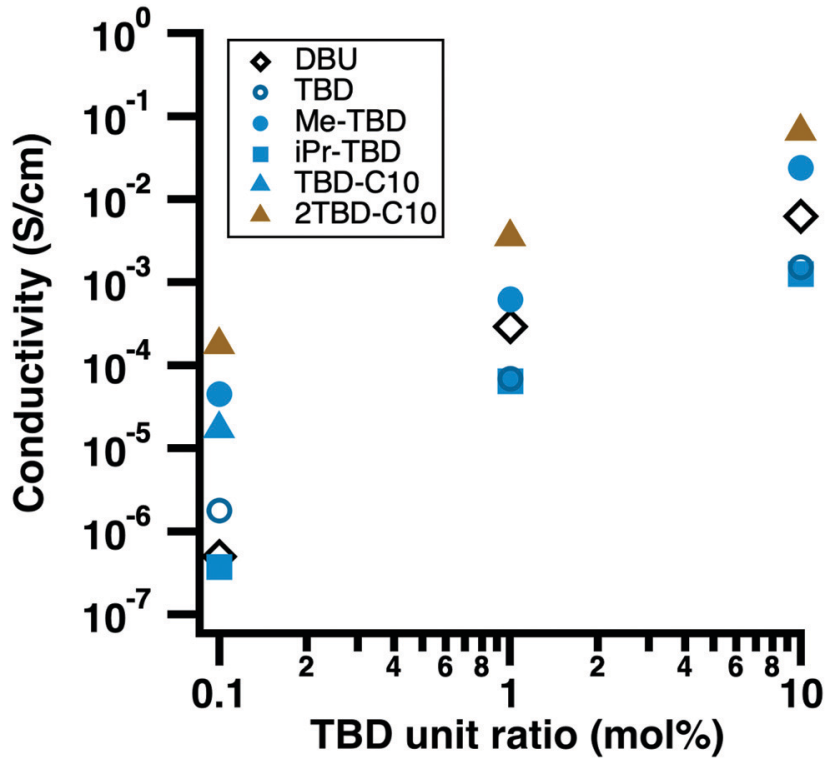

Fig. 2 Electrical conductivities of films of $\mathrm{PC}_{61} \mathrm{BM}$ doped with TBDderivatives and DBU as a function of the molar ratio. TBD-C10 has a data point only at $0.1 \mathrm{~mol} \%$ because films could not be cast at higher molar ratios.

films of $\mathrm{PC}_{61} \mathrm{BM}$. The branched isopropyl derivative, iPr-TBD, gave similar electrical conductivities as TBD suggesting that the alkylation itself is not the sole origin of the increase. The addition of relatively long linear alkyl groups, i.e. TBD-C10, led difficulties in casting doped films at high molar ratios due to dewetting of the films from the substrate. We attribute this issue to the surfactant-like nature of its structure of TBD-C10. This issue was eliminated by using the dimer, 2TBD-C10, which was processable at all concentration used.

$\mathrm{PC}_{61} \mathrm{BM}$ films doped by 2TBD-C10 are more tolerant to thermal annealing than those by TBDs with short side chains. The conductivity of 1 mol\% 2TBD-C10 doped PCBM film increased from $3.5 \times 10^{-3}$ to $7.4 \times 10^{-3} \mathrm{~S} \mathrm{~cm}^{-1}$ after thermal annealing on a hot plate in nitrogen at $150{ }^{\circ} \mathrm{C}$ for $30 \mathrm{~min}$, whereas that of Me-TBD doped one dropped from $6.2 \times 10^{-4}$ to $5.6 \times 10^{-5} \mathrm{~S} \mathrm{~cm}^{-1}$ in the same treatment. This change is wellcorrelated to the TGA data for the dopants that showed a higher decompositions temperature for longer chain derivatives. The improved processability of 2BD-C10 and its higher tolerance to thermal treatments led us to focus on this dopant relative to others in the series.

We measured grazing incident wide angle X-ray scattering (GIWAXS) to determine if there were signs of aggregation or changes in the structural order of doped $\mathrm{PC}_{61} \mathrm{BM}$ thin films. The scattering patterns of $\mathrm{PC}_{61} \mathrm{BM}$ films without dopant and with $10 \mathrm{~mol} \%$ of 2TBD-C10, Me-TBD, and iPr-TBD are almost identical (Fig. 3 and Fig. S9, ESI $\dagger$ ). They have two rings at around $q=0.7$ and $1.4 \AA^{-1}$ with full width at half maximum (FWHM) of about 0.20 and $0.15 \AA^{-1}$, respectively, indicating those films are amorphous as typically seen in fullerene films. We found that the peaks shift slightly toward lower $q$ range by $\approx 0.03 \AA^{-1}$ upon doping, which is a small shift given the FWHM of the peaks. Importantly, we do not observe any new peaks 

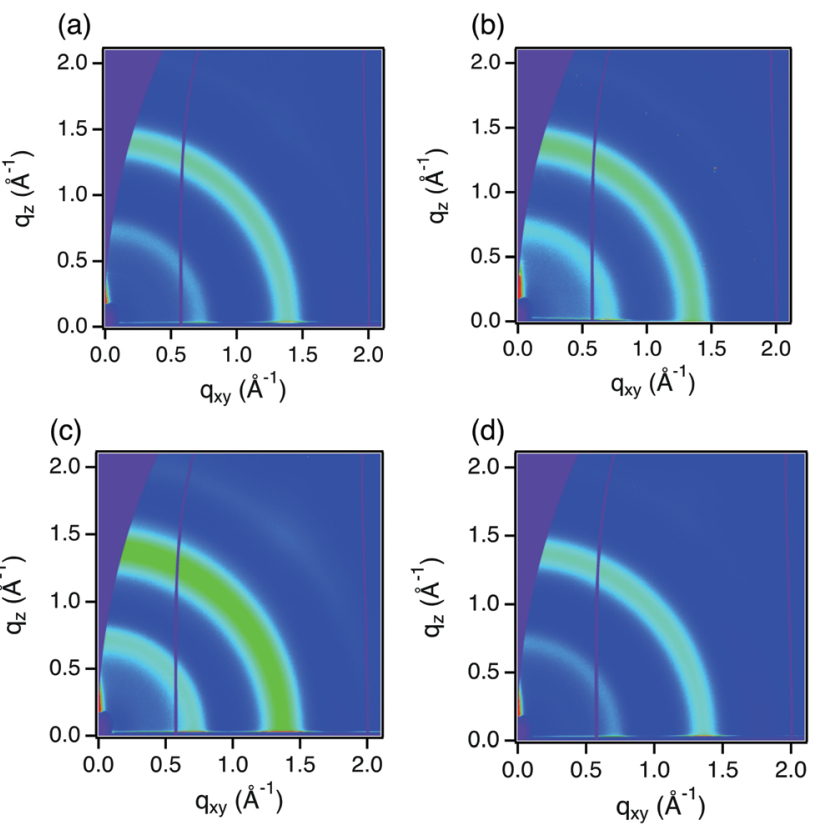

Fig. 3 2-Dimensional GIWAXS images of (a) pristine $P_{61} B M$, (b) $P C_{61} B M$ with 10 mol\% 2TBD-C10, (c) PC ${ }_{61} B M$ with 10 mol\% Me-TBD, and (d) $P_{61} C_{61} B M$ with 10 mol\% iPr-TBD

upon doping with 2TBD-C10, a solid dopant suggesting that there are no aggregates of the dopant and likely molecularly mixing of the compound with $\mathrm{PC}_{61} \mathrm{BM}$. If an adduct is formed between the dopant and $\mathrm{PC}_{61} \mathrm{BM}$, it does not strongly perturb the structure of doped $\mathrm{PC}_{61} \mathrm{BM}$ films relative to undoped films.

We found that addition of 2TBD-C10 leads to n-type doping of organic semiconductors beyond $\mathrm{PC}_{61} \mathrm{BM}$. We examined the doping of P(NDI2OD-T2), a well-studied naphthalenediimide based conjugated polymer, because it has been broadly used as a test case for n-type doping and it has an electron affinity near that of $\mathrm{PC}_{61} \mathrm{BM}^{7,9,19,24,28}$ Thin films of $\mathrm{P}(\mathrm{NDI} 2 \mathrm{OD}-\mathrm{T} 2)$ doped with 2TBD-C10 at $10 \mathrm{~mol} \%$ have an electrical conductivity of $7.0 \times 10^{-4} \mathrm{~S} \mathrm{~cm}^{-1}$ (Table 1). This value is comparable to value using (2-Cyc-DMBI $)_{2}\left(2.8 \times 10^{-3} \mathrm{~S} \mathrm{~cm}^{-1} \text { with } 11 \mathrm{~mol} \%\right)^{7}$ and N-DMBI $\left(8 \times 10^{-4} \mathrm{~S} \mathrm{~cm}^{-1} \text { with } 10 \mathrm{~mol} \%\right)^{24}$ as dopants. In contrast, TBD-C10 gives three orders of magnitude lower conductivity $\left(1.5 \times 10^{7} \mathrm{~S} \mathrm{~cm}^{-1}\right)$ in $10 \mathrm{~mol} \%$ doping, indicating that the dimer is significantly more effective. 2TBD-C10 also dopes ITIC, an accepter-donor-acceptor shape non-fullerene acceptor for organic photovoltaics, yielding conductivities of $4.3 \times 10^{-6}$ and $1.7 \times 10^{-6} \mathrm{~S} \mathrm{~cm}^{-1}$ with 10 and $1 \mathrm{~mol} \%$ doping, respectively. These relatively low conductivities are partly due to lower electron mobility in ITIC $\left(\sim 10^{-2} \mathrm{~cm}^{2} \mathrm{~V}^{-1} \mathrm{~s}^{-1}\right)$ than that of $\mathrm{PC}_{61} \mathrm{BM}\left(\sim 10^{-1} \mathrm{~cm}^{2} \mathrm{~V}^{-1} \mathrm{~s}^{-1}\right)$ based on measurements of fieldeffect transistors. $^{32}$

The scattering patterns of $\mathrm{P}(\mathrm{NDI} 2 \mathrm{OD}-\mathrm{T} 2)$ are also insensitive to doping with 2TBD-C10 and TBD-C10 (Fig. 4 and Fig. S10 $\mathrm{ESI} \dagger$ ). The scattering pattern of pristine P(NDI2OD-T2) show a $\pi$-staking feature at $1.6 \AA^{-1}$ in the out-of-plain direction and alkyl stacking features at 0.25 and $0.47 \AA^{-1}$ in the in-plane direction, indicating a face-on orientation of its crystalline moieties. Addition of 2TBD-10 or TBD-C10 does not result in
Table 1 Electrical conductivities $\left(\mathrm{S} \mathrm{cm}^{-1}\right)$ of thin films of organic semiconductors as a function of concentration of the TBD dopant

\begin{tabular}{|c|c|c|c|c|}
\hline & 2TBD-C10 & 2TBD-C10 & 2TBD-C10 & TBD-C10 \\
\hline Dopant concentration & $10 \mathrm{~mol} \%$ & $1 \mathrm{~mol} \%$ & $0.1 \mathrm{~mol} \%$ & $10 \mathrm{~mol} \%$ \\
\hline $\mathrm{PC}_{61} \mathrm{BM}$ & $6.5 \times 10^{-2}$ & $3.5 \times 10^{-3}$ & $1.8 \times 10^{-4}$ & $\mathrm{nd}^{b}$ \\
\hline $\mathrm{P}(\mathrm{NDI} 2 \mathrm{OD}-2 \mathrm{~T})$ & $7.0 \times 10^{-4}$ & $2.4 \times 10^{-6}$ & $\mathrm{nd}^{a}$ & $1.5 \times 10^{-7}$ \\
\hline ITIC & $4.3 \times 10^{-6}$ & $1.7 \times 10^{-6}$ & $\mathrm{nd}^{a}$ & $\mathrm{nd}^{b}$ \\
\hline
\end{tabular}

notable shift of the polymer originated peaks or appearance of new peaks. We thus conclude that the crystalline domains of the polymer are impenetrable to these TBD dopants, and the dopants reside in the amorphous regions. This conclusion is not unique to the TBD dopants and also holds true for conventional dopants such as N-DMBI as we previously reported. ${ }^{5}$

\section{Doping electron transport layers in perovskite solar cells}

Doping of the hole and electron transport layers in organic metal halide (perovskite) solar cells has proven to be a beneficially strategy for improving their performance. ${ }^{33-37}$ Organic amines have been used to improve carrier extraction in organic electron transport layers (ETLs) of perovskite solar cells. Polyethyleneimine (PEIE) has frequently been used as an interlayer to modify the work function at electrodes by doping or forming interfacial dipole layers. ${ }^{38,39} \operatorname{Poly}\left[\left(9,9-b i s\left(3^{\prime}\right.\right.\right.$-( $N, N$-dimethylamino) propyl)2,7-fluorene)-alt-2,7-(9,9-dioctylfluorene)] (PFN) has been used as an effective interlayer with $\mathrm{PC}_{61} \mathrm{BM}$ ETLs in perovskite solar cells, ${ }^{40}$ with some attributing the improvement due to doping. ${ }^{37}$ Co-polymers of PFN and napthalenediimides as ETLS have also shown to lead to good fill factors in solar cells as well (a)

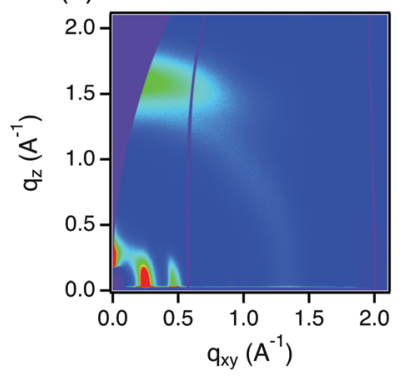

(c)

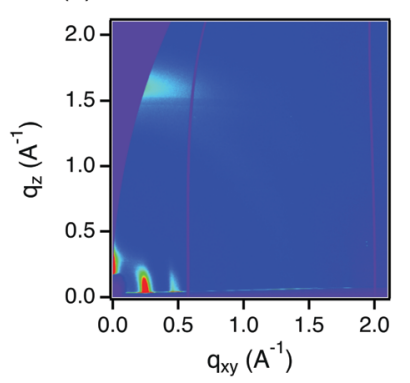

(b)

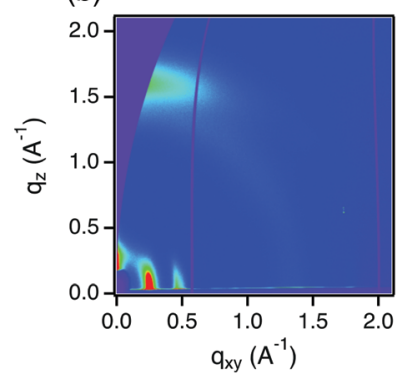

Fig. 4 2-Dimensional GIWAXS scattering of (a) pristine P(NDI2OD-T2), (b) P(NDI2OD-T2) with 10 mol\% 2TBD-C10, and (c) P(NDI2OD-T2) with 10 mol\% TBD-C10. 
(a)

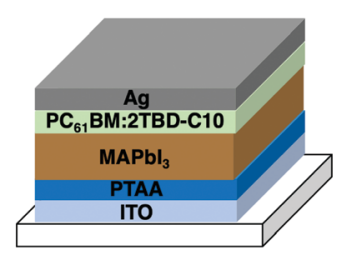

(b)

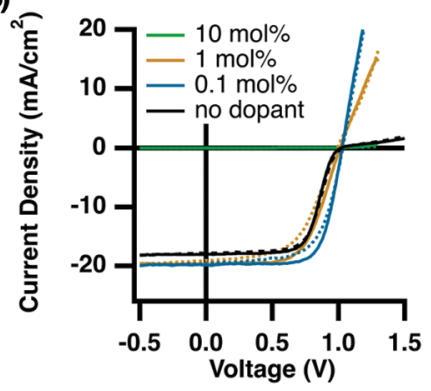

Fig. 5 (a) Schematic of the solar cell structure of glass/ITO $\left(20 \Omega \mathrm{sq}^{-1}\right) /$ polytriarylamine (PTAA, $\sim 5 \mathrm{~nm}$ )/MAPbl 3 ( $\sim 400 \mathrm{~nm}$ )/PC ${ }_{61} \mathrm{BM}$ :dopant $(\sim 100 \mathrm{~nm}) / \mathrm{Ag}(80 \mathrm{~nm})(\mathrm{b}) \mathrm{J}-V$ characteristics of $\mathrm{MAPbl}_{3}$ photovoltaics using $\mathrm{PC}_{61} \mathrm{BM}$ doped with $2 \mathrm{TBD}-\mathrm{C} 10$ in a ratio of (black) 0 mol\%, (blue) $0.1 \mathrm{~mol} \%$, (gold) $1 \mathrm{~mol} \%$ and (green) $10 \mathrm{~mol} \%$. Dashed lines represent forward scans, while solid lines reverse scans.

demonstrating the broad utility of aliphatic tertiary amine functionalities. ${ }^{41}$ The success of these materials suggested that the TBD-dopants would be compatible with perovskite solar cells.

To demonstrate the utility of the TBD-based dopants, we fabricated solar cells of methylammonium lead triiodide $\left(\mathrm{MAPbI}_{3}\right)$ with an inverted structure, i.e. ETL cast on top of the $\mathrm{MAPbI}_{3}$ layer (Fig. 5). We examined 2TBD-C10 doped $\mathrm{PC}_{61} \mathrm{BM}$ as the ETL to assess the impact of doping on the behavior of the solar cells. The device stack is glass/ITO $(20 \Omega$ $\left.\mathrm{sq}^{-1}\right) /$ polytriarylamine (PTAA, $\left.\sim 5 \mathrm{~nm}\right) / \mathrm{MAPbI}_{3}(\sim 400 \mathrm{~nm}) /$ $\mathrm{PC}_{61} \mathrm{BM}(\sim 100 \mathrm{~nm}) / \mathrm{Ag}(80 \mathrm{~nm})$. The results clearly show that doping $\mathrm{PC}_{61} \mathrm{BM}$ with 2TBD-C10 works to improves the performance with a clear optimal molar ratio of dopant (Table 2 and Fig. 5). The devices without doping give a power conversion efficiency (PCE) of $11.8 \%$ with kink in the current-voltage $(J-V)$ characteristic around the $V_{\mathrm{OC}}$ condition $\left(J=0 \mathrm{~mA} \mathrm{~cm} \mathrm{~cm}^{-2}\right)$. Because the $J_{\mathrm{SC}}\left(18.0 \mathrm{~mA} \mathrm{~cm}{ }^{-2}\right)$ of the solar cell is reasonable given the thickness of the $\mathrm{MAPbI}_{3}$ layer, the kink is a sign of an electron injection barrier at the $\mathrm{Ag} / \mathrm{PC}_{61} \mathrm{BM}$ interface due to Schottky barrier formation. When $\mathrm{PC}_{61} \mathrm{BM}$ is doped with $0.1 \mathrm{~mol} \%$ of 2TBD-C10, the kink disappears giving a PCE of $14.5 \%$ with improved fill-factor $(\mathrm{FF})$ of 0.71 . Further addition of the dopant, however, leads to deterioration of the device performance. With $1 \mathrm{~mol} \%$ of doping, $\mathrm{FF}$ is reduced to 0.61 while retaining the $V_{\mathrm{OC}}$ and $J_{\mathrm{SC}}$, giving a PCE of $12.3 \%$. With $10 \mathrm{~mol} \%$, the $J_{\mathrm{SC}}$ is almost entirely quenched and the solar cell has very poor performance. We previously found that increase the doping of ETLs can lead to decomposition of the surface of $\mathrm{MAPbI}_{3}$ by inducing release of iodine. ${ }^{42}$ It is possible that similar degradation happens here in the highly doped devices, increasing the

Table 2 Device parameters of $\mathrm{MAPbl}_{3}$ based photovoltaics with the structure: glass/ITO/PTAA/MAPbI ${ }_{3} / \mathrm{PC}_{61} \mathrm{BM}: 2 \mathrm{TBD}-\mathrm{C} 10 / \mathrm{Ag}$

\begin{tabular}{lllll}
\hline 2TBD-C10 (mol\%) & $V_{\mathrm{OC}}(\mathrm{V})$ & $J_{\mathrm{SC}}\left(\mathrm{mA} \mathrm{cm}^{-2}\right)$ & $\mathrm{FF}$ & PCE $(\%)$ \\
\hline 0 (not doped) & $1.02 \pm 0.00$ & $18.0 \pm 0.33$ & $0.64 \pm 0.01$ & $11.8 \pm 0.5$ \\
0.1 & $1.02 \pm 0.00$ & $19.8 \pm 0.15$ & $0.70 \pm 0.01$ & $14.4 \pm 0.17$ \\
1 & $1.00 \pm 0.02$ & $19.2 \pm 0.45$ & $0.60 \pm 0.02$ & $11.7 \pm 0.68$ \\
10 & $\sim 0.2$ & $<0.01$ & $\sim 0.2$ & $<0.1$
\end{tabular}

resistance at the $\mathrm{MAPbI}_{3} / \mathrm{PC}_{61} \mathrm{BM}$ interface and blocking charge extraction from the bulk of the active layer.

\section{Conclusions}

In conclusion, we have shown that triazabicylodecene-based compounds can effectively dope n-type organic semiconductors, including $\mathrm{PC}_{61} \mathrm{BM}$. Tethering two TBD moieties with a simple alkyl chain gave a solid dopant, 2TBD-C10, with high thermal stability above $250{ }^{\circ} \mathrm{C}$ and effective doping of a range of organic semiconductors. $\mathrm{PC}_{61} \mathrm{BM}$ films doped by 2TBD-C10 were the most tolerant to thermal annealing and reached inplane conductivities of $6.5 \times 10^{-2} \mathrm{~S} \mathrm{~cm}^{-1}$. Furthermore, using $\mathrm{PC}_{61} \mathrm{BM}$ doped with 2TBD-C10 as the electron transport layer (ETL) in $\mathrm{MAPbI}_{3}$ photovoltaics led to a $23 \%$ increase in performance, from $11.8 \%$ to $14.5 \%$ PCE. Although beyond the scope of this report, there may be added benefits of using superbases like the TBD series as n-type dopants with perovskite solar cells. The ability of TBD and its conjugate Lewis acid to complex, or react, with stray metal atoms, ${ }^{43,44} \mathrm{CO}_{2},{ }^{45,46}$ and reactive oxygen species ${ }^{47,48}$ could further improve the stability of devices.

\section{Conflicts of interest}

A patent has been filed by the authors on the use of TBDderivatives as dopants.

\section{Acknowledgements}

Work on the mechanism of doping was supported by NSF DMR 1808622. Portions of the research were carried out at the Advanced Light Source, supported by the Director, Office of Science, Office of Basic Energy Sciences, of the U.S. Department of Energy under Contract No. DEAC02-05CH11231. The research reported here made use of shared facilities of the UCSB MRSEC (NSF DMR 1720256), a member of the Materials Research Facilities Network (www.mrfn.org). Use was made of computational facilities purchased with funds from the National Science Foundation (CNS-1725797) and administered by the Center for Scientific Computing (CSC). The CSC is supported by the California NanoSystems Institute and the Materials Research Science and Engineering Center (MRSEC; NSF DMR 1720256) at UC Santa Barbara. The authors thank Prof. Fred Wudl (UCSB) for many helpful discussions on this work and for his many pioneering contributions to the field of materials chemistry.

\section{References}

1 B. Lüssem, C.-M. Keum, D. Kasemann, B. Naab, Z. Bao and K. Leo, Doped Organic Transistors, Chem. Rev., 2016, 116, 13714-13751.

2 B. Russ, A. Glaudell, J. J. Urban, M. L. Chabinyc and R. A. Segalman, Organic thermoelectric materials for energy harvesting and temperature control, Nat. Rev. Mater., 2016, 1, 1-14. 
3 S. Guo, S. B. Kim, S. K. Mohapatra, Y. Qi, T. Sajoto, A. Kahn, S. R. Marder and S. Barlow, n-Doping of Organic Electronic Materials using Air-Stable Organometallics, Adv. Mater., 2012, 24, 699-703.

4 F. Wudl, G. M. Smith and E. J. Hufnagel, Bis-1,3-dithiolium chloride: an unusually stable organic radical cation, J. Chem. Soc., Chem. Commun., 1970, 1453.

5 M. Bendikov, F. Wudl and D. F. Perepichka, Tetrathiafulvalenes, Oligoacenenes, and Their Buckminsterfullerene Derivatives: The Brick and Mortar of Organic Electronics, Chem. Rev., 2004, 104, 4891-4946.

6 F. Li, A. Werner, M. Pfeiffer, K. Leo and X. Liu, Leuco Crystal Violet as a Dopant for n-Doping of Organic Thin Films of Fullerene $\mathrm{C}_{60}$, J. Phys. Chem. B, 2004, 108, 17076-17082.

7 B. D. Naab, S. Zhang, K. Vandewal, A. Salleo, S. Barlow, S. R. Marder and Z. Bao, Effective Solution- and VacuumProcessed n-Doping by Dimers of Benzimidazoline Radicals, Adv. Mater., 2014, 26, 4268-4272.

8 X. Lin, B. Wegner, K. M. Lee, M. A. Fusella, F. Zhang, K. Moudgil, B. P. Rand, S. Barlow, S. R. Marder, N. Koch and A. Kahn, Beating the thermodynamic limit with photoactivation of n-doping in organic semiconductors, Nat. Mater., 2017, 16, 1209-1215.

9 E. E. Perry, C.-Y. Chiu, K. Moudgil, R. A. Schlitz, C. J. Takacs, K. A. O'Hara, J. G. Labram, A. M. Glaudell, J. B. Sherman, S. Barlow, C. J. Hawker, S. R. Marder and M. L. Chabinyc, High Conductivity in a Nonplanar n-Doped Ambipolar Semiconducting Polymer, Chem. Mater., 2017, 29, 9742-9750.

10 Y. Qi, S. K. Mohapatra, S. Bok Kim, S. Barlow, S. R. Marder and A. Kahn, Solution doping of organic semiconductors using airstable n-dopants, Appl. Phys. Lett., 2012, 100, 083305-4.

11 Y. Zhou, C. Fuentes-Hernandez, J. Shim, J. Meyer, A. J. Giordano, H. Li, P. Winget, T. Papadopoulos, H. Cheun, J. Kim, M. Fenoll, A. Dindar, W. Haske, E. Najafabadi, T. M. Khan, H. Sojoudi, S. Barlow, S. Graham, J.-L. Bredas, S. R. Marder, A. Kahn and B. Kippelen, A Universal Method to Produce Low-Work Function Electrodes for Organic Electronics, Science, 2012, 336, 327-332.

12 B. Russ, M. J. Robb, B. C. Popere, E. E. Perry, C.-K. Mai, S. L. Fronk, S. N. Patel, T. E. Mates, G. C. Bazan, J. J. Urban, M. L. Chabinyc, C. J. Hawker and R. A. Segalman, Tethered tertiary amines as solid-state n-type dopants for solutionprocessable organic semiconductors, Chem. Sci., 2016, 7, 1914-1919.

13 S. B. Schmidt, T. Biskup, X. Jiao, C. R. McNeill and M. Sommer, Controlling intermolecular redox-doping of naphthalene diimides, J. Mater. Chem. C, 2019, 7, 4466-4474.

14 S. Fabiano, S. Braun, X. Liu, E. Weverberghs, P. Gerbaux, M. Fahlman, M. Berggren and X. Crispin, Poly(ethylene imine) Impurities Induce n-doping Reaction in Organic (Semi)Conductors, Adv. Mater., 2014, 26, 6000-6006.

15 A. Cabrera-Espinoza, S. Collavini and J. L. Delgado, Doping strategies of organic n-type materials in perovskite solar cells: a chemical perspective, Sustain, Energy Fuels, 2020, 4, 3264-3281.
16 J. Panidi, J. Kainth, A. F. Paterson, S. Wang, L. Tsetseris, A. Emwas, M. A. McLachlan, M. Heeney and T. D. Anthopoulos, Introducing a Nonvolatile N-Type Dopant Drastically Improves Electron Transport in Polymer and SmallMolecule Organic Transistors, Adv. Funct. Mater., 2019, 29, 1902784.

17 A. Skiebe, A. Hirsch, H. Klos and B. Gotschy, [DBU]C60. Spin pairing in a fullerene salt, Chem. Phys. Lett., 1994, 220, 138-140.

18 H. Klos, I. Rystau, W. Schütz, B. Gotschy, A. Skiebe and A. Hirsch, Doping of C60 with tertiary amines: TDAE, DBU, DBN. A comparative study, Chem. Phys. Lett., 1994, 224, 333-337.

19 L. Hu, T. Liu, J. Duan, X. Ma, C. Ge, Y. Jiang, F. Qin, S. Xiong, F. Jiang, B. Hu, X. Gao, Y. Yi and Y. Zhou, An Amidine-Type n-Dopant for Solution-Processed Field-Effect Transistors and Perovskite Solar Cells, Adv. Funct. Mater., 2017, 27, 1703254.

20 R. Ge, F. Qin, L. Hu, S. Xiong and Y. Zhou, High fill factor over $82 \%$ enabled by a biguanide doping electron transporting layer in planar perovskite solar cells, Front. Optoelectron., 2018, 11, 360-366.

21 R. Pratt, B. Lohmeijer, D. Long, R. Waymouth and J. Hedrick, J. Am. Chem. Soc., 2006, 128, 4556-4557.

$22 \mathrm{X}$. Fu and C.-H. Tan, Mechanistic considerations of guanidinecatalyzed reactions, Chem. Commun., 2011, 47, 8210.

23 Z. Tang, J. Wang, A. Melianas, Y. Wu, R. Kroon, W. Li, W. Ma, M. R. Andersson, Z. Ma, W. Cai, W. Tress and O. Inganäs, Relating open-circuit voltage losses to the active layer morphology and contact selectivity in organic solar cells, J. Mater. Chem. A, 2018, 6, 12574-12581.

24 R. A. Schlitz, F. G. Brunetti, A. M. Glaudell, P. L. Miller, M. A. Brady, C. J. Takacs, C. J. Hawker and M. L. Chabinyc, Solubility-Limited Extrinsic n-Type Doping of a High Electron Mobility Polymer for Thermoelectric Applications, $A d v$. Mater., 2014, 26, 2825-2830.

25 P. Gund, Guanidine, trimethylenemethane, and 'Y-delocalization.' Can acyclic compounds have 'aromatic' stability?, J. Chem. Educ., 1972, 49, 100.

26 A. Dworkin, R. Naumann, C. Seigfred, J. M. Karty and Y. Mo, Y-Aromaticity: Why Is the Trimethylenemethane Dication More Stable than the Butadienyl Dication?, J. Org. Chem., 2005, 70, 7605-7616.

27 C. Burkholder, W. Dolbier and M. Medebielle, J. Org. Chem., 1998, 63, 5385-5394.

28 S. Wang, H. Sun, U. Ail, M. Vagin, P. O. A. Persson, J. W. Andreasen, W. Thiel, M. Berggren, X. Crispin, D. Fazzi and S. Fabiano, Thermoelectric Properties of Solution-Processed n-Doped Ladder-Type Conducting Polymers, Adv. Mater., 2016, 28, 10764-10771.

29 G. Yu, J. Gao, J. C. Hummelen, F. Wudl and A. J. Heeger, Polymer Photovoltaic Cells: Enhanced Efficiencies via a Network of Internal Donor-Acceptor Heterojunctions, Science, 1995, 270, 1789-1791.

30 M. Schwarze, C. Gaul, R. Scholz, F. Bussolotti, A. Hofacker, K. S. Schellhammer, B. Nell, B. D. Naab, Z. Bao, D. Spoltore, 
K. Vandewal, J. Widmer, S. Kera, N. Ueno, F. Ortmann and K. Leo, Molecular parameters responsible for thermally activated transport in doped organic semiconductors, Nat. Mater., 2019, 18, 242-248.

31 S. Rossbauer, C. Müller and T. D. Anthopoulos, Comparative Study of the N-Type Doping Efficiency in Solutionprocessed Fullerenes and Fullerene Derivatives, Adv. Funct. Mater., 2014, 24, 7116-7124.

32 Y. Park, C. Fuentes-Hernandez, X. Jia, F. A. Larrain, J. Zhang, S. R. Marder and B. Kippelen, Measurements of the field-effect electron mobility of the acceptor ITIC, Org. Electron., 2018, 58, 290-293.

33 Y. Guo, W. Sato, K. Inoue, W. Zhang, G. Yu and E. Nakamura, n-Type doping for efficient polymeric electron-transporting layers in perovskite solar cells, J. Mater. Chem. A, 2016, 4, 18852-18856.

34 J. Zhou, J. Hou, X. Tao, X. Meng and S. Yang, Solutionprocessed electron transport layer of n-doped fullerene for efficient and stable all carbon based perovskite solar cells, J. Mater. Chem. A, 2019, 7, 7710-7716.

35 J. Wang, W. Fu, S. Jariwala, I. Sinha, A. K.-Y. Jen and D. S. Ginger, Reducing Surface Recombination Velocities at the Electrical Contacts Will Improve Perovskite Photovoltaics, ACS Energy Lett., 2019, 4, 222-227.

36 N. K. Noel, S. N. Habisreutinger, A. Pellaroque, F. Pulvirenti, B. Wenger, F. Zhang, Y.-H. Lin, O. G. Reid, J. Leisen, Y. Zhang, S. Barlow, S. R. Marder, A. Kahn, H. J. Snaith, C. B. Arnold and B. P. Rand, Interfacial charge-transfer doping of metal halide perovskites for high performance photovoltaics, Energy Environ. Sci., 2019, 12, 3063-3073.

37 S. Shao, J. Liu, H.-H. Fang, L. Qiu, G. H. ten Brink, J. C. Hummelen, L. J. A. Koster and M. A. Loi, Efficient Perovskite Solar Cells over a Broad Temperature Window: The Role of the Charge Carrier Extraction, Adv. Energy Mater., 2017, 7, 1701305.

38 S. van Reenen, S. Kouijzer, R. A. J. Janssen, M. M. Wienk and M. Kemerink, Origin of Work Function Modification by Ionic and Amine-Based Interface Layers, Adv. Mater. Interfaces, 2014, 1, 1400189.
39 H. Zhou, Q. Chen, G. Li, S. Luo, T.-B. Song, H.-S. Duan, Z. Hong, J. You, Y. Liu and Y. Yang, Interface engineering of highly efficient perovskite solar cells, Science, 2014, 345, 542-546.

40 J. You, Y. (Michael) Yang, Z. Hong, T.-B. Song, L. Meng, Y. Liu, C. Jiang, H. Zhou, W.-H. Chang, G. Li and Y. Yang, Moisture assisted perovskite film growth for high performance solar cells, Appl. Phys. Lett., 2014, 105, 183902.

41 C. Sun, Z. Wu, H.-L. Yip, H. Zhang, X.-F. Jiang, Q. Xue, Z. $\mathrm{Hu}, \mathrm{Z}$. Hu, Y. Shen, M. Wang, F. Huang and Y. Cao, Amino-Functionalized Conjugated Polymer as an Efficient Electron Transport Layer for High-Performance PlanarHeterojunction Perovskite Solar Cells, Adv. Energy Mater., 2016, 6, 1501534.

42 E. E. Perry, J. G. Labram, N. R. Venkatesan, H. Nakayama and M. L. Chabinyc, N-Type Surface Doping of MAPbI ${ }_{3}$ via Charge Transfer from Small Molecules, Adv. Electron. Mater., 2018, 4, 1800087.

43 P. J. Bailey and S. Pace, The coordination chemistry of guanidines and guanidinates, Coord. Chem. Rev., 2001, 214, 91-141.

44 F. T. Edelmann, Advances in Organometallic Chemistry, Elsevier, 2013, vol. 61, pp. 55-374.

45 Z.-Z. Yang, Y.-N. Zhao and L.-N. He, $\mathrm{CO}_{2}$ chemistry: taskspecific ionic liquids for $\mathrm{CO}_{2}$ capture/activation and subsequent conversion, RSC Adv., 2011, 1, 545.

46 C. Villiers, J.-P. Dognon, R. Pollet, P. Thuéry and M. Ephritikhine, An Isolated $\mathrm{CO}_{2}$ Adduct of a Nitrogen Base: Crystal and Electronic Structures, Angew. Chem., Int. Ed., 2010, 49, 3465-3468.

47 C. M. Geiselhart, C. W. Schmitt, P. Jöckle, H. Mutlu and C. Barner-Kowollik, A Guanidine-Based Superbase as Efficient Chemiluminescence Booster, Sci. Rep., 2019, 9, 14519.

48 N. Watanabe, A. Wakatsuki, H. K. Ijuin, Y. Kabe and M. Matsumoto, Organic superbase-induced chemiluminescent decomposition of a hydroxyaryl-substituted dioxetane: Unique effect of a bifunctional guanidine base on the chemiluminescence profile of a bicyclic dioxetane bearing a 4-(benzoxazol-2-yl)-3,5-dihydroxyphenyl moiety, Tetrahedron Lett., 2018, 59, 971-977. 